\title{
Diagnosis and Treatment of Acute Appendicitis in the Localization of Vermiform Process in the Cavity of the Female Pelvis
}

\author{
Shaposhnikov Veniamin Ivanovich* \\ Kuban Medical Institute, Russia
}

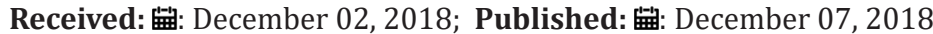

*Corresponding author: Shaposhnikov Veniamin Ivanovich, Professor of surgical diseases, Kuban Medical Institute, Krasnodar, Russia

\begin{abstract}
The author describes the 47 observation appendicitis when localizing vermiform process in the cavity of the female pelvis. All of these women developed the disease is extremely atypical, resulting in primary hospitals in gynaecology department about anticipated adnexitis. Only with the development of acute widespread peritonitis has been implemented, which enabled the laparotomy to find out the true cause of the disease. The author describes the symptoms of atypical appendicitis forms and methods of their treatment.
\end{abstract}

Keywords: Atypical; Acute Appendicitis; Female Pelvis; Peritonitis

\section{Introduction}

Expressed by the signs of appendicitis, which allow putting the correct diagnosis is already in the primary medical examination, identified only half of patients seeking [1,2]. The rea-sons that make it difficult to diagnose this disease include localization of the vermiform pro-cess in the cavity of the female pelvis [3,4]. In order to ascertain the reasons arising difficulties in diagnosing this disease, we determined the interrelationship between individual symptoms of acute appendicitis and vermiform process localization features in the abdomen at each individual patient [5]. 240 were analyzed observations of acute appendicitis. Out of the total number of these patients only $94(39.1 \%)$ There were pronounced symptoms, 109 (45.2\%) erased, and 37 (15.7\%) atypical. Under typical (pronounced) symptoms of acute appendicitis patients imply symptom Kocher, painful muscle strain in the right iliac region and positive symptom Shchyotkina Bljumberga [6,7]. Abnormal lack the above symptoms and pain localized in the area of the navel, above the vagina, in the right podreberie and left iliac region. There is a loose stools and pain when urinating. When all of these symptoms form erased are questionable. The least informative disease leaked when localizing vermiform process in the pelvic cavity (24.4\%), between loops of small intestine (5.5\%), podpe-chenochnom space $(3.7 \%)$, retrocekalno (24.4\%), zabrjushinno (14.6\%), loose infiltrate (11\%), as well as at the boundary of his spikes (17.4\%) [5]. When a minor appendicitis erased some diagnostic importance of additional clinical tests $[1,3,5]$. Only in the medical literature described above
120 the symptoms of this disease. Many of them differ little from each other. For this reason, a particular clinical value are only some of them, namely symptoms: Sitkovskogo, Rovzinga, Bartome Mihelsona, Promptovoj, Obrascova, kashlevogo Jolt, local flatulence cecum, rectal and vaginal the study, as well as dynamic analysis of changes in white blood. In the most questionable observations, and it was in 6 out of 109 (5.5\%), only laparoscopy allows to recognize the nature of the disease. In recognizing the same acute peritonitis great importance attached to indirect measurement of intraabdominal pressure [7-9]. These methods surveys allow you to not only be suspected in a patient presence of acute appendicitis, but also determine the localization process in the abdominal cavity. For example, the symptom Obrascova is indicative of retrocekalnoj and Exemplary retroperitoneal localization process and Promptovoj on spajanii it with the body of the uterus, or with her right broad ligament. Thus, in the arsenal of the surgeon have additional methods for the diagnosis of acute appendicitis in any localization vermiform pro-cess. This avoids diagnostic errors in clinical practice. The issue on this study.

\section{Materials and Methods}

Watched 47 women with inflammatory infiltration (VI) pelvic cavity between the ages of 18 to 48 years old, a cause which was destructive modified vermiform process. All these women were previously treated in the gynaecology department at adnexitis. At $44(93.6 \%)$ of them developed the phenomenon of widespread 
peritonitis. On the advice of the surgeon was invited. Diagnosis of peritonitis unclear etiology was not in doubt, and the operation took place. (6.4\%) and 3 have the same patient's symptoms common acute peritonitis. They only had complaints of persistent pain in the abdomen and frequent loose stools. By palpation and perkutorno through the front abdominal wall inflammatory infiltrate is not defined. Only vaginal study allowed the surgeon to suspect they have a form of atypical appendicitis-occurred a sharp increase abdominal pain when moving the uterus to the left. All these three patients during an operation around the uterus revealed loose infiltration, which man-aged to destroy, and then run appendjektomiju. The remaining 44 women performed the operation on acute peritonitis unclear etiology. In the abdominal cavity they had discovered the inflammatory infiltration of pelvic cavity in 3-phase of his development, he did not have a uniform structure that is tightly cohesive fabric between them were covered with friable conglomeration of large seal, the sigmoid and small intestines. After its destruction under it stripped the already dense infiltration, which included the cecum, vermiform process and uterine appendages. Clearly defined the area of the collapse of the tissues in the form of plane travel, through which the ulcer pelvis reported free abdominal cavity. Through this move made cautious finger abscess cavity audit, but without complete destruction of its walls. Audit from $18(40,9 \%)$ of them, it was found that he had died of gangrenous samoamputacija vermiform process. His necrotic tissues were removed. Peritonizacii same Stump Sprouts are not produced, because it was impossible. Others have 26 (59.1\%) patients that body had a holistic view. Vermiform process they have been deleted, and its stump perito-nizirovana separate nodal joints. At the end of the operation carried out drainage tubes both iliac areas. The same area of primary lesion peritonitis drained through the rear set vagina. Patients received antibiotics, vitamins and other traditional means of therapy.

\section{Resultants}

Postoperative period all 47 women went without complications. Treatment lasted from 3 to 5 weeks and ended all patient's recovery.

\section{Discussion}

Analysis of the observations showed that in matters of diagnosis of acute appendicitis, vermiform process during localization in the cavity of the female pelvic organs, there are a number of outstanding issues. Some assistance in determining the causes of pain in the abdomen, these patients can have knowledge of the symptoms of atypical forms of this disease. Additional assistance in this process can be achieved through the study of preoperative values intra-abdominal pressure. Features of this form of treatment of acute appendicitis are characterized by the fact that the inflammation in the pelvic cavity, these patients had initially taken for Gynaecological Pathology and only then, if the abscess ruptures in the free abdomen, were operational treatments, but for acute peritonitis. Only during laparotomy revealed the true reason of acute peritonitis. Acute appendicitis in these observations has been relatively benign, that was associated with the localization of the hearth of inflammation in the pelvic cavity is happening its delimitation three-dimensional tissues and organs located in the pelvic cavity from the rest abdominal cavity. Positive role played and drainage method of hearth-inflammation through the rear set vagina.

\section{Conclusion}

A characteristic feature of the development and course of acute appendicitis when localizing hearth inflammation in the cavity of the female pelvis, abdominal pain was the adoption for the development of women has acute gynaecological diseases. For this reason, treatment they have initially been purely conservative nature. Only when abscedirovanii infiltration followed by a breakthrough free abscess abdominal cavity, the operation was performed, during which the specific nature of the pathological process in the pelvic cavity. Relatively the same favorable during the inflammatory process can explain the peculiarities of development of otgranichivajushhego adhesions in the pelvic cavity and its drainage efficiency.

\section{Acknowledgement}

The Purpose of Isslevovanijaj highlight the difficulties of diagnosing acute appendicitis when localizing vermiform process in the cavity of the female pelvis.

\section{References}

1. Zhidovinov GI, Maskin SS, Mmatyukhin VV, Klimovich IN (2009) Diagnosis and treatment of syndrome of endogenous intoxication in peritonitis of different etiology. Spb p. 28-37.

2. Shaposhnikov VI (2004) Treatment of acute peritonitis. Publisher Stadtgespräch pp. 366s.

3. Gorbunov SS, Korczak MV, Oberemtnko AI (1977) Difficulties of preoperative differential diagnosis appendicitis and stroke the ovary mountain. Surgery p. 9-12.

4. Podzolkova NM (2005) Differential diagnostics in gynecology. GEOTARHONEY pp. 520.

5. Veliev NA, Hasanova DN, Ismaylov VF (2009) Score severity of peritonitis in intra-abdominal hypertension syndrome dependence and its pathogenetic implications. Spb p. 22-28.

6. Erjuhin IA, Shlyapnikov SA (2006) Peritonitis: Guide for emergency surgery the abdominal organs. pp. S461-S495.

7. Pickhardt PJ, Shimony JS, Heiken JP, Buchman TG, Fisher AJ (1999) The abdominal compartment syndrome CT findings. AJR Am J Roentgenol 173(3): 575-579.

8. Fusco MA, Martin RS, Chang MC (2001) Estimation of intraabdominal pressure by bladder pressure measurement validity and methodology. J Trauma 50(2): 297-302.

9. Kron JL, Harman PK, Nolan SP (1984) The measurement of intraabdominal pressure as a criterion for abdominal re-exploration. Ann Surg 199(1): 28-30. 
ISSN: 2574-1241

DOI: 10.26717/BJSTR.2018.11.002160

Shaposhnikov Veniamin Ivanovich. Biomed J Sci \& Tech Res

(C) (P) This work is licensed under Creative

Submission Link: https://biomedres.us/submit-manuscript.php

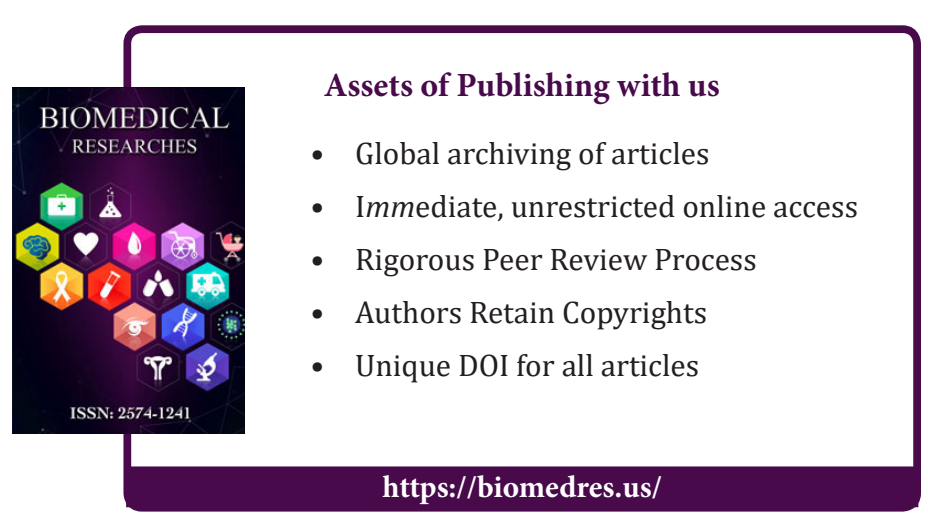

